\title{
Leucopis annulipes larvae (Diptera: Chamaemyiidae) use a furtive predation strategy within aphid colonies
}

\author{
BRUNo FRÉCHETTE, FrançoIs LAROUCHE and Éric LUCAS
}

\author{
Université du Québec à Montréal (UQAM), Groupe de Recherche en Écologie Comportementale et Animale (GRECA), \\ Département de Sciences Biologiques, C.P. 8888, Succ. Centre-Ville, Montréal, Québec, H3C 3P8 Canada; \\ e-mail: frechette_bruno@yahoo.ca
}

Key words. Predation strategy, active-searching predator, furtive predator, Chamaemyiidae, Leucopis annulipes, Cecidomyiidae, Aphidoletes aphidimyza, Coccinellidae, Harmonia axyridis, Acyrthosiphon pisum

\begin{abstract}
A laboratory experiment was conducted to determine whether the predation strategy of larvae of the aphidophagous silver fly Leucopis annulipes Zetterstedt (Diptera: Chamaemyiidae) is furtive, as are larvae of the aphidophagous midge Aphidoletes aphidimyza Rondani (Diptera: Cecidomyiidae), or active like aphidophagous ladybird beetle larvae (Coleoptera: Coccinellidae). The impact of L. annulipes larvae on pea aphid, Acyrthosiphon pisum (Harris) (Hemiptera: Aphididae), colony disturbance was evaluated and compared with that of the furtive predator A. aphidimyza and the active-searching ladybird beetle Harmonia axyridis Pallas. Results indicate that aphids showed significantly fewer defensive acts (dropping, walking away, wriggling) in the presence of $L$. annulipes larvae than of ladybird beetle larvae. Furthermore, the impact of $L$. annulipes larvae on aphid colony disturbance was similar to that of $A$. aphidimyza and to a control treatment without predators. These results clearly indicate that $L$. annulipes larvae use a furtive predation strategy.
\end{abstract}

\section{INTRODUCTION}

Most aphidophagous predators, such as ladybirds and lacewing larvae, use an active-searching strategy that elicits aphid defensive behaviour (Dixon, 1958; Losey \& Denno, 1998b; Lucas \& Brodeur, 2001). One known exception is the furtive predation strategy used by larvae of Aphidoletes aphidimyza Rondani (Diptera: Cecidomyiidae) (Lucas \& Brodeur, 2001). Unlike activesearching predators, A. aphidimyza larvae live within aphid colonies, trigger little defensive reaction by aphids, and do not cause significant disruption of the colony structure (Lucas \& Brodeur, 2001). For A. aphidimyza, one obvious advantage of furtive predation is that the aphids in the colony in which they live, do not disperse, which lower the probability of food shortage. Lucas \& Brodeur (2001) demonstrated that another possible advantage of furtive predation is protection from intraguild predation via a dilution effect. Since $A$. aphidimyza larvae are highly susceptible to intraguild predation (Lucas et al., 1998; Hindayana et al., 2001), living within a high density aphid colony reduces the risk of being preyed upon.

In Quebec, Canada, silver fly Leucopis spp. (Chamaemyiidae: Diptera) larvae are commonly encountered within apple aphid colonies (Bouchard et al., 1982; Tourneur et al., 1992). However, very little is known about the ecology of most members of this group. Since Leucopis spp. larvae are usually found within undisrupted aphid colonies, it is possible that their hunting strategy is similar to that of $A$. aphidimyza. Tracewski (1983) observed that Leucopis sp. nr. albipuncta eggs are usually laid in group of 2-3 under apple leaves in New Hampshire. As for $A$. aphidimyza (Kozár et al., 1994; Stewart \& Walde, 1997; Brown, 2004; Fréchette et al., 2008), their abundance is highly correlated with aphid density (Tracewski, 1983). In many systems Leucopis spp. are observed only when aphid densities reach moderate to high densities (Tracewski, 1983; Carroll \& Hoyt, 1984; Fox et al., 2004).

However, significant behavioural differences between Leucopis spp. and A. aphidimyza larvae may also exist. For instance, Leucopis spp. larvae are probably more active than A. aphidimyza larvae. In barley, Gaimari \& Turner (1997) observed that $1^{\text {st }}$ and $2^{\text {nd }}$ instar larvae of Leucopis ninae Tanasijtshuk and L. gaimarii Tanasijtshuk tend to stay within the aphid colony where their eggs were laid, while the $3^{\text {rd }}$ instar larvae (the last before pupation) are more mobile and even move between aphid colonies and plants. Such mobility has never been reported for A. aphidimyza.

The aim of this experiment was thus to determine whether the predation strategy of Leucopis annulipes Zetterstedt matched more closely the definition of furtive or active-searching predation strategy. The impact of $L$. annulipes larvae on pea aphid, Acyrthosiphon pisum (Harris) (Hemiptera: Aphididae), colony disturbance was thus compared to that of $A$. aphidimyza larvae, which are known as furtive predators, and Harmonia axyridis Pallas (Coleoptera: Coccinellidae) larvae, which are activesearching predators.

\section{MATERIAL AND METHODS}

\section{Biological material}

Leucopis annulipes larvae were collected in an apple orchard located in Saint-Bruno-de-Montarville, near Montreal, QC, Can- 
ada, in September 2006. This species was identified by Stephen D. Gaimari (California Department of Food and Agriculture) and voucher specimens are deposited in the National Museum of Natural History, Washington, DC (USNM). Leucopis annulipes larvae were found on apple trees near colonies of Aphis pomi De Geer and / or Aphis spiraecola Pagenstecher (Hemiptera: Aphididae). Captured individuals were then reared in the laboratory mainly following Gaimari \& Turner (1996b) methodology. Both adults and larvae were kept in the same plastic framed cages (35 $\times 35 \times 35 \mathrm{~cm})$ covered with muslin. Larvae were reared on broad bean plants, Vicia faba L., infested with either A. pisum or Aphis fabae Scopoli (Hemiptera: Aphididae). New plants were added about once a week. Discarded plants were cut and kept in the cages for about 2 weeks in order to allow adult emergence from pupae. Adults were fed a mixture of honey and yeast spread on the outer surface of the cage in order to avoid adults becoming stuck in this diet. Cages were held at $23-25^{\circ} \mathrm{C}, \mathrm{RH}$ 24-30\%, 16L : 8D.

The $A$. aphidimyza larvae used in this experiment came from the commercial supplier Pant-Prod Québec (Laval, Qc, Canada). As for L. annulipes, adults and larvae of A. aphidimyza were reared in the same cages $(35 \times 45 \times 70 \mathrm{~cm})$. Larvae were reared on broad bean plants infested with both A. pisum and A. fabae. New plants were added about once a week. As A. aphidimyza pupae develop in the soil, pots in which discarded plants grew were kept in the cages for 3 weeks. Adults were fed a mixture of water and commercial sugar (1/10) provided on a cotton wool. Conditions for rearing were the same as for L. annulipes.

The Asian ladybird beetle $H$. axyridis used in the experiment came from a stock culture maintained in the laboratory, which is refreshed yearly with field-captured individuals. Adults were kept in cages $(35 \times 35 \times 35 \mathrm{~cm})$ along with broad bean plants infested with $A$. pisum and A. fabae. Moreover, adults were also fed with sugar water, crushed pollen, and Sitotroga cerealella Olivier eggs (Lepidoptera: Gelechiidae). Ladybird beetle egg masses were isolated in Petri dishes and larvae reared therein fed on an artificial diet of crushed pollen and S. cerealella eggs.

\section{Impact of three predators on aphid colony disturbance}

Experiments were performed on broad bean plants at $23-25^{\circ} \mathrm{C}$, RH $24-30 \%, 16 \mathrm{~L}: 8 \mathrm{D}$. One aphid colony was introduced into a clip-cage on the abaxial surface of a leaf on each experimental plant at least $24 \mathrm{~h}$ before the beginning of the experiment. The clip cage was then removed, and aphid colonies were standardized to about $12-14 \mathrm{~A}$. pisum individuals aged 2-4 days. After colony standardisation, a delay of $10 \mathrm{~min}$ was allowed before the beginning of the experiment. During this 10-min period, the colony was schematized, i.e. each individual aphid was given a number and its position determined. A. pisum was chosen for this experiment since this aphid species shows a high level of defense which is readily observed (Nelson \& Rosenheim, 2006).

One predator per experimental plant was then introduced near the petiole of the aphid infested leaf, marking the beginning of the observation period. Three experimental treatments using a different predator were compared, that is (1) A. aphidimyza, (2) L. annulipes, and (3) H. axyridis. Moreover, a control treatment without a predator was also recorded. Each of the 4 treatments were replicated 25 times. In order to eliminate the potential effect of predator size on aphid colony disturbance, development stages were chosen so that the predators were of similar size, i.e. $1^{\text {st }}$ and early $2^{\text {nd }}$ instar $H$. axyridis larvae, and 3-4 mm long $A$. aphidimyza and $L$. annulipes larvae, which corresponds to a $3^{\text {rd }}$ instar L. annulipes larvae (Sluss \& Foote, 1971, 1973; Tracewski, 1983; Gaimari \& Turner, 1996a). A controversy still exists about the number of $A$. aphidimyza larval stages (see
Lucas et al., 1998). Observations were made over a 45-min period. Predators that did not interact with the aphid colony were discarded and replaced.

Aphid defensive behaviour was observed following the introduction of predators, and classified in one of the three categories: (1) walking away from the feeding site, (2) dropping off the plant and (3) wriggling and kicking. For each aphid defensive behaviour observed, it was noted whether it was a consequence of a direct interaction with the predator (following physical contact) or an indirect interaction (without physical contact between aphids and the predator). Indirect interaction could results from aphid reaction to alarm pheromone, physical contact with conspecifics, and / or plant-borne vibrations caused by the predator. Also, for each predator, the attack success was also noted in terms of the number of prey consumed / the number of contacts with prey.

\section{Statistical analysis}

As aphid colony size varied from 12-14, the number of defensive acts observed was divided by the initial number of individuals in the colony. The mean number of defensive acts / individual for each colony were then compared using KruskalWallis tests since the data were not normally distributed (tested with Shapiro-Wilk). For the comparison of total defensive acts, the number of reactions in the control treatment that would have been attributed to defensive behaviour (walking away, dropping, wriggling and kicking) in any other treatment were recorded. For the comparison of both direct and indirect defensive behaviour, the control treatment was excluded from the analysis since aphid reactions could not be segregated into direct and indirect interactions in the absence of predators. The proportions of each defensive act were compared between predators using a $\chi^{2}$ analysis computed by hand (Zar, 1999). The proportions of successful attacks were arcsin squared root transformed and compared using a Kruskal-Wallis test. Calculations were made using the statistical software JMP (SAS Institute, 2001).

\section{RESULTS}

\section{Defensive behaviour}

Every $H$. axyridis and L. annulipes individual observed ate only one aphid per aphid colony. A. aphidimyza larvae were sometimes observed surrounded by 2 dead aphids.

When all defensive behaviour resulting from both direct and indirect interactions with predators are pooled,

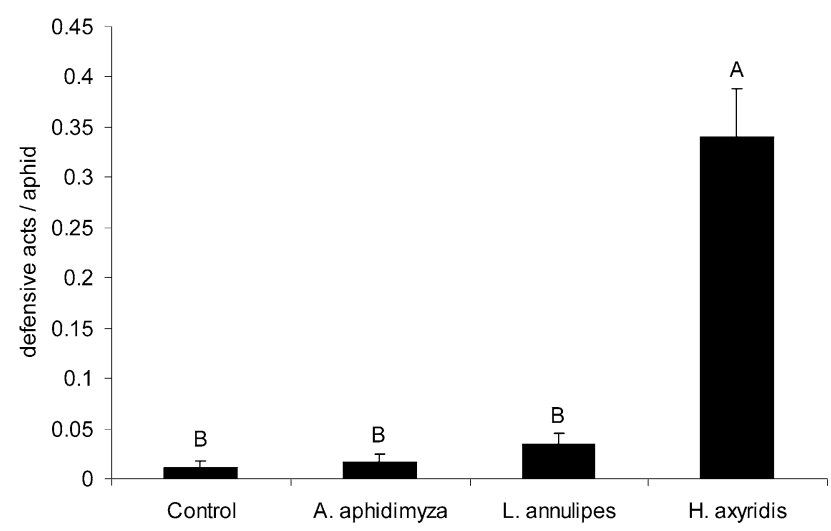

Fig. 1. The average number of defensive acts / aphid recorded when approached by a larva of Aphidoletes aphidimyza $(\mathrm{n}=$ $25)$, Leucopis annulipes $(\mathrm{n}=25)$ and Harmonia axyridis $(\mathrm{n}=$ $25)$, and in the control treatment. Different letters indicate significant differences $(P<0.05)$. 


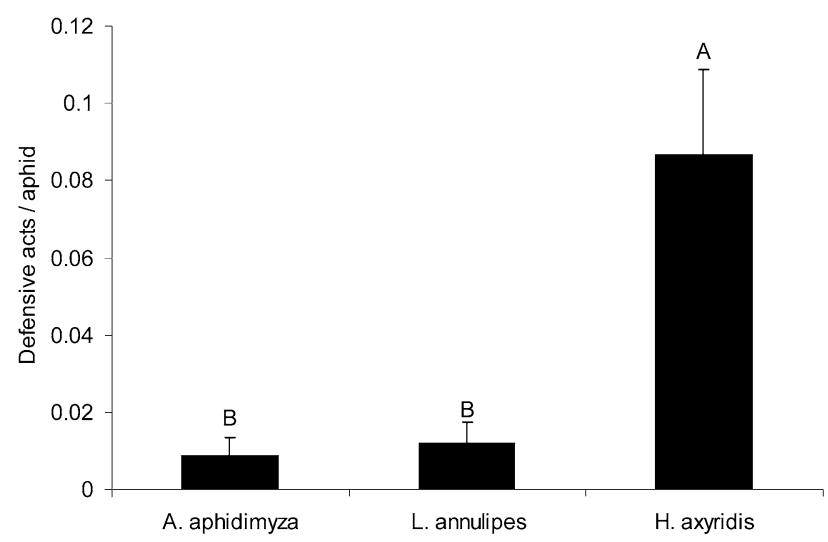

Fig. 2. The average number of defensive acts / aphid resulting from a direct interaction with an Aphidoletes aphidimyza larva $(\mathrm{n}=25)$, a Leucopis annulipes larva $(\mathrm{n}=25)$ and a Harmonia axyridis larva $(\mathrm{n}=25)$. Different letters indicate significant differences $(P<0.05)$.

a significant difference is observed between treatments (Kruskall-Wallis; $\chi^{2}=57.46$, d.f. $=3, P<0.001$ ) (Fig. 1). The total number of defensive acts / aphid was significantly higher in the presence of $H$. axyridis larvae than in all the other treatments $(P<0.05)$, which were not different from one another $(P>0.05)$.

The number of defensive acts resulting from direct interactions was significantly different between treatments (Kruskall-Wallis; $\chi^{2}=20.48$, d.f. $=2, P<0.001$ ) (Fig. 2). Direct interaction with $H$. axyridis elicited more defensive behaviour than with the 2 other predators $(P<$ $0.05)$. The number of defensive acts resulting from direct interaction was not significantly different between $L$. annulipes and $A$. aphidimyza $(P<0.05)$.

The number of defensive acts elicited by indirect interactions was also significantly different between treatments (Kruskall-Wallis; $\chi^{2}=47.88$, d.f. $=2, P<0.001$ ) (Fig. 3). Their number was greater in the presence of $H$. axyridis larvae than in the 2 other treatments $(\mathrm{P}<0.05)$. However, there were no differences between the L. annulipes and $A$. aphidimyza treatments $(P>0.05)$.

\section{Types of defensive behaviour}

In the control treatment, no defensive behaviour was observed with the exception of 4 aphids, which were observed walking, a behaviour that would have been classified as a Walking away and a defensive act in any of the 3 other treatments. Among the 3 predator treatments, no significant difference was observed in the proportion of the different defensive behaviour types $\left(\chi^{2}=6.062, P>\right.$ 0.05) (Table 1). This indicates that the different types of

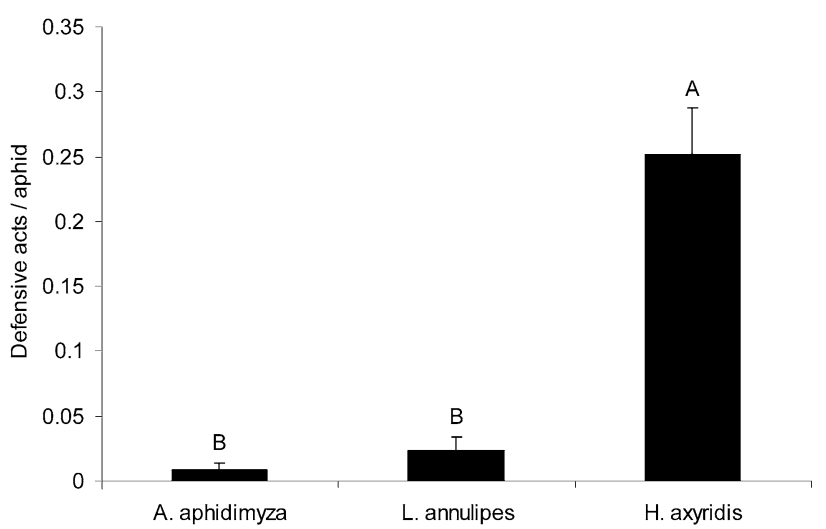

Fig. 3. The average number of defensive acts / aphid resulting from indirect interaction with an Aphidoletes aphidimyza larva $(\mathrm{n}=25)$, a Leucopis annulipes larva $(\mathrm{n}=25)$ and a Harmonia axyridis larva $(\mathrm{n}=25)$. Different letters indicate significant differences $(P<0.05)$.

aphid defensive behaviour were not associated with predator identity.

\section{Attack success}

A significant difference was observed in the attack success of the 3 predators (Kruskall-Wallis; $\chi^{2}=19.57$, d.f. $=$ $2, P<0.001)$. The attack success of $H$. axyridis $(63.7 \pm$ $6.4 \%$ ) was significantly lower than that of $L$. annulipes $(90.0 \pm 4.1 \%)$ and A. aphidimyza $(96.0 \pm 2.8 \%)(P<$ $0.05)$. However, no difference was observed in the attack success of $L$. annulipes and $A$. aphidimyza $(P>0.05)$. That is, $H$. axyridis larvae contacted more aphids before being able to capture one than either L. annulipes or $A$. aphidimyza larvae.

\section{DISCUSSION}

The results of this experiment clearly indicate that the predation strategy of $L$. annulipes larvae is similar to that of A. aphidimyza larvae. Unlike active-searching predators, L. annulipes larvae are furtive predators and do not disrupt aphid colonies.

Among the active-searching predators, different predator species induce different levels of aphid defensive behaviour (Losey \& Denno, 1998b; Nelson \& Rosenheim, 2006). For example, Nelson \& Rosenheim (2006) recorded that the ratio of disturbed : consumed $A$. pisum on alfalfa Medicago sativa L. was $19: 2$ when the predator was Nabis sp. (Heteroptera: Nabidae) and $71: 1$ when the predator was Hippodamia convergens Guerin de Méneville (Coleoptera: Coccinellidae). Losey \& Denno (1998b) also record that adult Coccinella septempunctata L. (Coleoptera: Coccinellidae) disturb A. pisum

TABLE 1. The number of defensive acts recorded when aphids were approached by a larva of Aphidoletes aphidimyza, Leucopis annulipes and Harmonia axyridis.

\begin{tabular}{ccccc}
\hline Predator & $\mathrm{n}$ & Dropping & Walking away & Wriggling \\
\hline A. aphidimyza & 25 & 1 & 3 & 2 \\
L. annulipes & 25 & 6 & 6 & 0 \\
H. axyridis & 25 & 45 & 57 & 10 \\
\hline
\end{tabular}


colonies more than heteropteran predators. The last authors propose that predator body size, searching behaviour, and consumption rate differences may explain the different impacts on the aphid colonies. Losey \& Denno (1998b) also propose that the differences in the aphid response to predator type may depend on the volume of alarm pheromone released, the level of substrate vibration produced by the predators or a combination of these two factors.

In our study, since predator body size was standardised, this factor should not have affected the results. However, the searching behaviour of $H$. axyridis larvae differs from that of the two dipters: $H$. axyridis larvae are campodeiform and probably create more leaf vibration than the vermiform A. aphidimyza and L. annulipes larvae, which move by crawling. Also, $H$. axyridis larvae move faster within the colony and have a lower attack success, generating more disturbance than the slow moving and more efficient furtive predators. Attack success should, however, not be considered as a key factor since Lucas \& Brodeur (2001) found that aphid colonies are significantly more disrupted by Chrysoperla rufilabris Burmeister (Neuroptera: Chrysopidae) $1^{\text {st }}$ instar larvae than by $A$. aphidimyza larvae, even though both have similar attack successes.

Within a single species, Dixon (1958) observed that the ratio of dropping : walking shown by Microlophium evansi (Theobald) (Hemiptera: Aphididae) aphids when approached by an adult Adalia decempunctata (L.) (Coleoptera: Coccinellidae) was greater than when approached by a $2^{\text {nd }}$ instar larva. He proposed that this might be due to a decrease in the ratio of the speed of the aphid : speed of the predator when $A$. decempunctata is older, making the Walking away response of aphids less effective. This is supported by the fact that early and late $1^{\text {st }}$ instar larvae, which are of similar size but differ in speed of movement, elicited different defensive behaviour patterns: a greater proportion of aphids escaped predation by Dropping when approached by the faster late instar larvae than the early instar larvae. However, the author also stressed that different coccinellid instars with a similar speed of movement also elicited different defensive behaviour patterns, suggesting that size may also play a role.

In our experiment, no significant differences were observed in the proportions of aphid defensive behaviour types elicited by the three predators, which suggests that aphids show similar behaviour when reacting to activesearching and furtive predators. This contrasts with other studies that have found different types of defensive behaviour in response to different predator species. For example, Brodsky \& Barlow (1986) have demonstrated that $A$. pisum had a greater tendency to drop than back away from an approaching adult of the ladybird beetle Adalia bipunctata (L.) (Coleoptera: Coccinellidae), but showed the opposite tendency when approached by a larva of the syrphid Metasyrphus corollae (Fab.) (Diptera: Syrphidae). They suggest that backing away is effective in the presence of a slow moving predator such as syrphid larvae. However, it may not be effective when approached by a fast moving predator such as ladybird beetles, in which situation dropping could be more effective. The difference between our results and those presented by Brodsky \& Barlow (1986) could be attributed to the fact that $A$. aphidimyza and L. annulipes triggered very few defensive acts, lowering the probability of finding a statistical difference between treatments. A higher number of replicates may have resulted in results similar to those of Brodsky \& Barlow (1986).

The furtive predation strategy of $A$. aphidimyza is thought to have a double advantage. First, $A$. aphidimyza larvae have a low dispersal capacity (see Wilbert, 1973) and survival would be greatly compromised if they would have to search for a new aphid colony in order to complete the development. Second, A. aphidimyza larvae suffer from intraguild predation by other aphidophagous predators (Lucas et al., 1998; Hindayana et al., 2001). However, Lucas \& Brodeur (2001) demonstrated that intraguild predation on $A$. aphidimyza larvae by the larvae of the lacewing $C$. rufilabris is reduced in denser aphid colonies. These authors demonstrated that A. aphidimyza larvae benefit from a dilution effect in large aphid colonies.

Leucopis annulipes larvae could benefit from the same double advantage of furtive predation. As for $A$. aphidimyza larvae, Leucopis spp. $1^{\text {st }}$ and $2^{\text {nd }}$ instar larvae also have a low dispersal capacity. Although $3^{\text {rd }}$ instar may have a higher mobility (Gaimari \& Turner, 1997), the probability of finding a new aphid colony in an architecturally complex environment such as an apple tree is probably low. Although movement between aphid colonies by $3^{\text {rd }}$ instar larvae is recorded in grassland by Gaimari \& Turner (1997), the possibility of completing development within a single aphid colony would nevertheless increase L. annulipes larvae probability of survival. This should be tested experimentally. Also, Leucopis spp. larvae are occasionally victims of intraguild predation by ladybird beetle and lacewing larvae (Sluss \& Foote, 1973), and some species are known to exhibit cannibalism (Gaimari \& Turner, 1997). Leucopis annulipes larvae may thus lower their predation risk by benefiting from a dilution effect as is the case for A. aphidimyza (Lucas \& Brodeur, 2001). However, the susceptibility of L. annulipes larvae to intraguild predation in aphid colonies of different sizes remains to be tested.

From a biological control point of view, the aphid colony disturbance caused by active-searching predators may be an advantage, particularly when aphid displacement enhances their mortality risk, for instance through synergistic predation (Losey \& Denno, 1998a). As a result, the real mortality rate inflicted by colonydisruptive predators could be higher than their simple consumption rate. As such, active-searching predators could be more effective for the biological control of aphid species with a high tendency to drop or walk away when attacked. However, even though the strategy adopted by the furtive predators seems a priori less appropriate for a knock-down effect on aphid colonies, the role they play 
in the long term regulation of aphid populations can be important (Meadow et al., 1985).

ACKNOWLEDGEMENT. We would like to thank S.D. Gaimari, California Department of Food \& Agriculture, for Leucopis annulipes identification and rearing advice, L. Voynaud for technical advice and A. Sentis for technical assistance. We are also grateful to two anonymous reviewers for helpful comments on the manuscript.

\section{REFERENCES}

Bouchard D., Tourneur J.-C. \& Paradis R.O. 1982: Le complexe entomophage limitant les populations d'Aphis pomi de Geer (Homoptera: Aphididae) dans le sud-ouest du Québec. Données préliminaires. Ann. Soc. Entomol. Québec 27: 80-93.

Brodsky L.M. \& Barlow C.A. 1986: Escape responses of the pea aphid, Acyrthosiphon pisum (Harris) (Homoptera: Aphididae): influence of predator type and temperature. Can. J. Zool. 64: 937-939.

Brown M.W. 2004: Role of aphid predator guild in controlling spirea aphid population on apple in West Virginia, USA. Biol. Contr. 29: 189-198.

CARroll D.P. \& Hoyt S.C. 1984: Natural enemies and their effects on apple aphid, Aphis pomi DeGeer (Homoptera: Aphididae), colonies on young apple trees in central Washington. Environ. Entomol. 13: 469-481.

DiXon A.F.G. 1958: The escape responses shown by certain aphids to the presence of the coccinellid Adalia decempunctata (L.). Trans. R. Entomol. Soc. Lond. 110: 319-334.

Fox T.B., Landis D.A., Cardoso F.F. \& Difonzo C.D. 2004: Predators suppress Aphis glycines Matsumura population growth in soybean. Environ. Entomol. 33: 608-618.

Fréchette B., Chouinard G., Brodeur J., Vanoosthuyse F. \& LuCAS É. 2008: Apple aphid, Aphis spp., and predator populations in a young, high-density, and scab-resistant apple orchard: the impact of ground cover and cultivar. Eur. J. Entomol. 105: 521-529.

GAIMARI S.D. \& TURNer W.J. 1996a: Immature stages of Leucopis ninae Tanasijtshuk and two variant populations of Leucopis gaimarii Tanasijtshuk (Diptera: Chamaemyiidae) feeding on Russian wheat aphid, Diuraphis noxia (Mordvilko) (Homoptera: Aphididae). Proc. Entomol. Soc. Wash. 98: 647-666.

Gaimari D.S. \& TURner W.J. 1996b: Methods for rearing aphidophagous Leucopis spp. (Diptera: Chamaemyiidae). J. Kans. Entomol. Soc. 69: 363-369.

GAIMARI D.S. \& TURNER W.J. 1997: Behavioral observations on the adults and larvae of Leucopis ninae and Leucopis gaimarii (Diptera: Chamaemyiidae), predators of Russian wheat aphid, Diuraphis noxia (Homoptera: Aphididae). J. Kans. Entomol. Soc. 70: 153-159.

Hindayana D., Mayhöfer R., Scholz D. \& Poehling H.-M. 2001: Intraguild predation among the hoverfly Episyrphus balteatus de Geer (Diptera: Syrphidae) and other aphidophagous predators. Biol. Contr. 20: 236-246.

KozÁr F., Brown M.W. \& Lightner G. 1994: Spatial distribution of homopteran pests and beneficial insects in an orchard and its connection with ecological plant protection. J. Appl. Entomol. 117: 519-529.

Losey J.E. \& DenNo R.F. 1998a: Positive predator-predator interactions: enhanced predation rates and synergistic suppression of aphid populations. Ecology 79: 2143-2152.

LosEy J.E. \& DenNo R.F. 1998b: The escape response of pea aphids to foliar-foraging predators: factors affecting dropping behaviour. Ecol. Entomol. 23: 53-61.

Lucas E. \& Brodeur J. 2001: A fox in sheep's clothing: furtive predators benefit from the communal defense of their prey. Ecology 82: 3246-3250.

Lucas E., Coderre D. \& Brodeur J. 1998: Intraguild predation among aphid predators: characterization and influence of extraguild prey density. Ecology 79: 1084-1092.

Meadow R.H., Kelly W.C. \& Shelton A.M. 1985: Evaluation of Aphidoletes aphidimyza (Dip.: Cecidomyiidae) for control of Myzus persicae (Hom.: Aphididae) in greenhouse and field experiments in the United States. Entomophaga 30: 385-392.

Nelson E.H. \& Rosenheim J.A. 2006: Encounters between aphids and their predators: the relative frequencies of disturbance and consumption. Entomol. Exp. Appl. 118: 211-219.

SAS Institute 2001: JMP IN®, Version 4. Start Statistics: a Guide to Statistics and Data Analyses Using JMP ${ }^{\circledR}$ and JMP $I N ®$ Software. Duxbury, Pacific Grove, California, 656 pp.

SLuss T.P. \& Foote B.A. 1971: Biology and immature stages of Leucopis pinicola and Chamaemyia polystigma (Diptera: Chamaemyiidae). Can. Entomol. 105: 1443-1452.

Stuss T.P. \& Foote B.A. 1973: Biology and immature stages of Leucopis verticalis (Diptera: Chamaemyiidae). Can. Entomol. 103: $1427-1434$.

Stewart H.C. \& Walde S.J. 1997: The dynamics of Aphis pomi De Geer (Homoptera: Aphididae) and its predator, Aphidoletes aphidimyza (Rondani) (Diptera: Cecidomyiidae), on apple in Nova Scotia. Can. Entomol. 129: 627-636.

Tourneur J.-C., Bouchard D. \& Pilon J.-G. 1992: Le complexe des ennemis naturels des pucerons en pommeraie au Québec. In Vincent C. \& Coderre D. (eds): La Lutte Biologique. Gaëtan Morin, Boucherville, Québec, pp. 179-193.

TRACEWSKI K.T. 1983: Description of the immature stages of Leucopis sp. nr. albipuncta (Diptera: Chamaemyiidae) and their role as predators of the apple aphid, Aphis pomi (Homoptera: Aphididae). Can. Entomol. 115: 735-742.

WiLbert H. 1973: Zur Suchfähigkeit der Eilarven von Aphidoletes aphidimyza (Diptera: Cecidomyiidae). Entomol. Exp. Appl. 16: 514-524.

ZAR J.H. 1999: Biostatistical analysis. 4th ed. Prentice Hall, Upper Saddle River, New Jersey, 931 pp.

Received September 18, 2007; revised and accepted November 5, 2007 